\title{
Reduction of dynamin 1 in the hippocampus of aged mice is associated with the decline in hippocampal-dependent memory
}

\author{
DAE YOUNG YOO ${ }^{1}$, HYO YOUNG JUNG ${ }^{1}$, JONG WHI KIM ${ }^{1}$, HEE SUN YIM ${ }^{2}$, DAE WON KIM ${ }^{2}$, HAJIN NAM ${ }^{3}$, \\ JUN GYO SUH ${ }^{3}$, JUNG HOON CHOI ${ }^{4}$, MOO-HO WON ${ }^{5}$, YEO SUNG YOON ${ }^{1}$ and IN KOO HWANG ${ }^{1}$ \\ ${ }^{1}$ Department of Anatomy and Cell Biology, College of Veterinary Medicine and Research Institute for Veterinary Science, \\ Seoul National University, Seoul 08826; ${ }^{2}$ Department of Biochemistry and Molecular Biology, \\ Research Institute of Oral Sciences, College of Dentistry, Kangneung-Wonju National University, Gangneung, \\ Gangwon 25457; ${ }^{3}$ Department of Medical Genetics, College of Medicine, Hallym University, Chuncheon, \\ Gangwon 24252; ${ }^{4}$ Department of Anatomy, College of Veterinary Medicine; ${ }^{5}$ Department of Neurobiology, \\ School of Medicine, Kangwon National University, Chuncheon, Gangwon 24341, Republic of Korea
}

Received August 28, 2015; Accepted September 7, 2016

DOI: $10.3892 / \mathrm{mmr} .2016 .5804$

\begin{abstract}
Dynamin 1 is a known synaptic protein, which has is key in the presynaptic regulation of endocytosis. The present study investigated the association between age and the observed changes in Morris water maze performance, and immunoreactivity and protein levels of dynamin 1 in the mouse hippocampal formation. In addition, the effects of dynasore, an inhibitor of dynamin 1, on the hippocampal dependent memory were determined to elucidate the correlation between dynamin 1 and memory. In the training phase of the Morris water maze task, the mean escape latency of the aged group (24 months old) was significantly longer, compared with that of the adult group (4 months old), although the average swimming speed and the total distance traveled during the probe trial were similar in the two groups. In the aged group, the time spent locating the target platform was significantly longer and the time spent in the correct quadrant was significantly shorter, compared with those in the adult group. In the adult group, a moderate level of dynamin 1 was detected in the hippocampal CA1 and CA3 regions, and in the dentate gyrus. In the aged group, the immunoreactivity of dynamin 1 was almost eliminated in the CA3 region and the dentate gyrus. In addition, the protein levels of dynamin 1 in the brain were significantly lower in the aged group, compared with those in the adult group. The direct infusion of dynasore, significantly reduced the contextual memory, compared with that of
\end{abstract}

Correspondence to: Professor In Koo Hwang, Department of Anatomy and Cell Biology, College of Veterinary Medicine and Research Institute for Veterinary Science, Seoul National University, Gwanak-ro 599, Gwanakgu, Seoul 08826, Republic of Korea E-mail: vetmed2@snu.ac.kr

Key words: dynamin 1, hippocampus, memory, natural aging, water maze test animals in the vehicle-treated group. These results suggested that dynamin 1 was susceptible to the aging process, and that a reduction in dynamin 1 may result in hippocampal-dependent memory deficits by disrupting endocytosis and the release of neurotransmitters.

\section{Introduction}

Aging is a component of the natural life cycle, causing various morphological, functional and biochemical alterations in the body, including cognitive decline, and reductions in neuronal cytoskeleton dynamics and synaptic plasticity (1-4). In addition, the hippocampus, a critical region for memory, is vulnerable to damage during the aging process, possibly due to alterations in protein levels, which accompany the early stages of Alzheimer's disease $(5,6)$.

Among synaptic proteins, dynamin is known to be important in the regulation of endocytosis (7) and synaptic vesicle recycling (8). Dynamin has three isoforms, all of which are expressed in nerve terminals, however, dynamin 1 is detected at high levels in nerve terminals of the hippocampus (9). Dynamin 1 is one of several molecules involved in the pinching off of synaptic vesicles, releasing them from the membrane during exocytosis, and then allowing the vesicles to dock and re-enter the synaptic vesicle pool to be refilled for further neurotransmitter release (10). Inhibition of the vesicle recycling process or a decrease in the readily releasable pool of synaptic vesicles affects the ability of the hippocampus to function. Previously, it was reported that the pharmacological inhibition of dynamin markedly impairs hippocampal-dependent associative memory formation (11).

Several lines of evidence have demonstrated that dynamin 1 is associated with the aging processes occurring in the hippocampus (12-14), Alzheimer's disease (15-18) and nicotine dependence $(19,20)$. However, there are conflicting reports regarding alterations to the expression levels of dynamin 1 and associations with neurological disorders and aging. Several studies have reported an increase in dynamin 1 in the 
hippocampus associated with aging $(13,14)$ and Alzheimer's disease $(15,18)$. By contrast, other studies have found a decrease in dynamin 1 in the hippocampus associated with Alzheimer's disease $(15,21)$ and nicotine dependence $(19,20)$.

However, few studies have been performed to assess age-related changes to the hippocampal expression of dynamin 1 in C57BL/6 mice, a widely used experimental animal model. The present study investigated changes to the immunoreactivity and protein levels of dynamin 1 in the hippocampus and its correspondence with age. In addition, the present study observed the effects of the inhibition of dynamin 1 on the hippocampal-dependent memory in adult mice because dynamin 1 is essential for synaptic vesicle recycling and memory formation.

\section{Materials and methods}

Experimental animals. Young adult (4 month-old) and aged (24 month-old) male C57BL/6 J mice were purchased from Japan SLC, Inc. (Shizuoka, Japan). The 24 month old mice were selected as the aged group as, in humans, this age in mice is equivalent to an age of 69 years (22). The animals were placed in a mouse cage (five mice/cage) in conventional conditions. They were maintained under controlled temperature $\left(23^{\circ} \mathrm{C}\right)$ and humidity $(60 \%)$ on a 12 -h light-dark cycle. The mice were fed a commercial pelleted diet (Purina chow diet 38057; Purina Korea, Seoul, Korea) and water ad libitum. The procedures for the handling and caring of animals followed the Guide for the Care and Use of Laboratory Animals issued by the Institute of Laboratory Animal Resources, and the experimental protocol was approved by the Institutional Animal Care and Use Committee of Seoul National University (Seoul, Korea). All the experiments were performed to minimize the number of animals used and the any suffering caused by the procedures used in the present study.

Morris water maze (MWM) task. To confirm the memory deficits in the aged group, spatial memory was assessed using the MWM task according to a previous study (23). The water maze assessments were performed in order to ensure objectivity in blind conditions. At 3 days post-training, the time required for an individual mouse to locate the submerged platform within $2 \mathrm{~min}$ (escape latency) and the swimming distance were monitored using a digital camera and a computer system for 4 days consecutively, with four trials per day. For each trial, the mouse ( $n=10$ per group) was placed in the water facing the wall at one of four starting positions and released. The swimming speed and the time required for the mouse to locate the hidden platform were recorded via a visual tracking system (Noldus Information Technology, Wageningen, The Netherlands). The probe test was performed on day 5; the platform was removed and the time that the mouse spent swimming in the target quadrant, and the time spent in the three non-target quadrants (right, left and opposite quadrants), were measured in the training and opposite quadrants in $60 \mathrm{sec}$. In addition, the number of times the mouse crossed over the platform site was recorded.

Tissue processing for histology. For histological analysis, the mice in the adult and aged groups ( $n=6$ per group) were terminally anesthetized the day following the MWM task with $1 \mathrm{~g} / \mathrm{kg}$ urethane (Sigma-Aldrich; Thermo Fisher Scientific, Inc., Waltham, MA, USA). The animals were perfused transcardially with $0.1 \mathrm{M}$ phosphate-buffered saline (PBS; $\mathrm{pH}$ 7.4) followed by $4 \%$ paraformaldehyde in $0.1 \mathrm{M}$ phosphate buffer ( $\mathrm{pH}$ 7.4). The brains were removed and post-fixed in the same fixative for $12 \mathrm{~h}$. The brain tissues were cryoprotected by infiltration with $30 \%$ sucrose overnight. Subsequently, $30-\mu$ m-thick brain sections were serially cut in the coronal plane using a cryostat (Leica Microsystems GmbH, Wetzler, Germany). The sections were collected in six-well plates containing PBS and stored in storage solution at $-20^{\circ} \mathrm{C}$ until further processing.

Immunohistochemistry. In order to obtain accurate data for immunohistochemistry, free-floating sections were carefully processed under the same conditions. Sections were selected located between -1.46 and $-2.46 \mathrm{~mm}$ posterior to the Bregma in reference to a mouse atlas (24). The sections were sequentially treated with $0.3 \%$ hydrogen peroxide in $0.1 \mathrm{M} \mathrm{PBS}$ at $25^{\circ} \mathrm{C}$ for 30 min and $10 \%$ normal goat serum in $0.1 \mathrm{M}$ PBS. They were then incubated with diluted polyclonal rabbit anti-dynamin 1 (1:200; cat. no. ab55397; Abcam, Cambridge, UK) overnight at $25^{\circ} \mathrm{C}$, and subsequently exposed to biotinylated goat anti-rabbit IgG (diluted 1:200; cat. no. BA-1000; Vector Laboratories, Inc., Burlingame, CA, USA) and streptavidin peroxidase complex (diluted 1:200, Vector Laboratories, Inc.) for $2 \mathrm{~h}$ at $25^{\circ} \mathrm{C}$. Subsequently, the sections were visualized by reaction with 3,3'-diaminobenzidine tetrahydrochloride for 1 min (Sigma-Aldrich; Thermo Fisher Scientific, Inc.). Digital images were captured with a BX51 light microscope (Olympus Corporation, Tokyo, Japan) equipped with a digital camera (DP72; Olympus Corporation) connected to a computer monitor.

Western blot analysis. To confirm the alterations in dynamin 1 with age, six mice from each group were sacrificed and for western blot analysis. Following sacrifice of the mice $(n=4$ per group) and removal of their brains, the hippocampi were dissected out with a surgical blade. The hippocampal tissues were pooled from tissues of three animals to increase the efficiency of normalization, and were homogenized in $50 \mathrm{mM}$ PBS (pH 7.4) containing $0.1 \mathrm{mM}$ ethylene glycol bis (2-aminoethyl Ether)- $N, N, N^{\prime}, N^{\prime}$-tetraacetic acid (pH 8.0), 0.2\% Nonidet $\mathrm{P}-40,10 \mathrm{mM}$ ethylendiamine-tetraacetic acid ( $\mathrm{pH} 8.0$ ), $15 \mathrm{mM}$ sodium pyrophosphate, $100 \mathrm{mM} \beta$-glycerophosphate, $50 \mathrm{mM} \mathrm{NaF}, 150 \mathrm{mM} \mathrm{NaCl}, 2 \mathrm{mM}$ sodium orthovanadate, $1 \mathrm{mM}$ phenylmethylsulfonyl fluoride and $1 \mathrm{mM}$ dithiothreitol (DTT). Following centrifugation at $16,000 \mathrm{x} \mathrm{g}$ for $20 \mathrm{~min}$ in a pre-cooled centrifuge, the protein level was determined in the supernatants using a Micro BCA protein assay kit with bovine serum albumin as the standard (Pierce; Thermo Fisher Scientific, Inc,). Aliquots containing $50 \mu \mathrm{g}$ of total protein were boiled at $95^{\circ} \mathrm{C}$ in a loading buffer containing $150 \mathrm{mM}$ Tris (pH 6.8), 3 mM DTT, 6\% SDS, $0.3 \%$ bromophenol blue and $30 \%$ glycerol for $5 \mathrm{~min}$. The aliquots were then loaded onto a $7.5 \%$ polyacrylamide gel. Following electrophoresis, the proteins were transferred from the gel onto nitrocellulose transfer membranes (Pall Corp., East Hills, NY, USA). To reduce background staining, the membranes were incubated 
with $5 \%$ non-fat dry milk in PBS containing $0.1 \%$ Tween 20 for $45 \mathrm{~min}$ at $25^{\circ} \mathrm{C}$, followed by incubation with rabbit anti-dynamin 1 (1:1,000; cat. no. ab55397; Abcam) at $4^{\circ} \mathrm{C}$ for $12 \mathrm{~h}$, peroxidase-conjugated anti-rabbit IgG (cat. no. PI-1000; Vector Laboratories, Inc.) and an use of an enhanced luminol-based chemiluminescence kit (Pierce; Thermo Fisher Scientific, Inc.). The blot was densitometrically scanned for quantification of the relative optical density of each band using ImageJ 1.59 software (NIH, Bethesda, MD, USA).

Effects of dynamin 1 inhibition on hippocampal-dependent memory. Dynasore (Sigma-Aldrich; Thermo Fisher Scientific, Inc.), an inhibitor of dynamin, was prepared as described in a previous study (11). Briefly, the dynasore was dissolved in DMSO to obtain a $200 \mathrm{mM}$ stock concentration and then stored at $-80^{\circ} \mathrm{C}$. Working solutions ( $80 \mu \mathrm{M}$ dynasore) were diluted in artificial cerebrospinal fluid (CSF) containing $124 \mathrm{mM} \mathrm{NaCl}$, $4.4 \mathrm{mM} \mathrm{KCl}, 1 \mathrm{mM} \mathrm{Na} \mathrm{HPO}_{4}, 25 \mathrm{mM} \mathrm{NaHCO}, 10 \mathrm{mM}$ glucose, $2 \mathrm{mM} \mathrm{CaCl}$ and $2 \mathrm{mM} \mathrm{MgCl}_{2}$, supplemented with $0.3 \% \mathrm{DMSO}$, in a low light environment. The animals $(\mathrm{n}=7$ in each group) were anesthetized with isoflurane and a 26-gauge guide cannula was placed above the dorsal hippocampi under stereotaxic coordination (anteroposterior, +2.4; mediolateral, \pm 1.5; dorsoventral, $-1.3 \mathrm{~mm}$ ) (24). At 1 week post-surgery, the same volume $(1.5 \mu \mathrm{l})$ of artificial CSF or $80 \mu \mathrm{M}$ dynasore was bilaterally injected through the intracerebral cannulas connected to a microsyringe with polyethylene tubing. At 20 min post-dynasore treatment, the mice were placed in a novel environment of a fear conditioning box and exposed to a mild foot electric shock ( $2 \mathrm{sec} ; 0.45 \mathrm{~mA})$ together with an auditory tone ( $30 \mathrm{sec} ; 85 \mathrm{~dB}$ sound at $2,800 \mathrm{~Hz}$ ). The electric shock was delivered during the last $2 \mathrm{sec}$ of the auditory tone. Freezing, whereby mice do not move other than to breathe, was scored using FreezeView (version 2.04; Coulbourn Instruments, Holliston, MA, USA). Learning was assessed $24 \mathrm{~h}$ later by measuring freezing behavior for $5 \mathrm{~min}$, in the chamber in which the mice were trained, in response to representation of the context without the auditory cue.

Statistical analysis. The data shown represent the mean of experiments performed for each experimental area. Differences among the means were statistically analyzed using a two-tailed Mann-Whitney $t$-test in order to elucidate differences between adult and aged groups. Analysis was performed using GraphPad Prism 5.01 software (GraphPad Software, Inc., La Jolla, CA, USA). All data are presented as the mean \pm standard error of the mean. $\mathrm{P}<0.05$ was considered to indicate a significantly significant difference.

\section{Results}

Spatial memory in aged mice. Spatial memory the in adult and aged mice was assessed using the MWM task. In the training trial of the escape latency task, the mean escape latency in the aged group was marginally longer, compared with the adult group on days 2 and 3 . However, there was no significant difference in the escape latency between the adult and aged groups. By day 4, the escape latency was significantly longer in the aged group, compared with that in the adult group (Fig. 1A). However, no significant differences
A

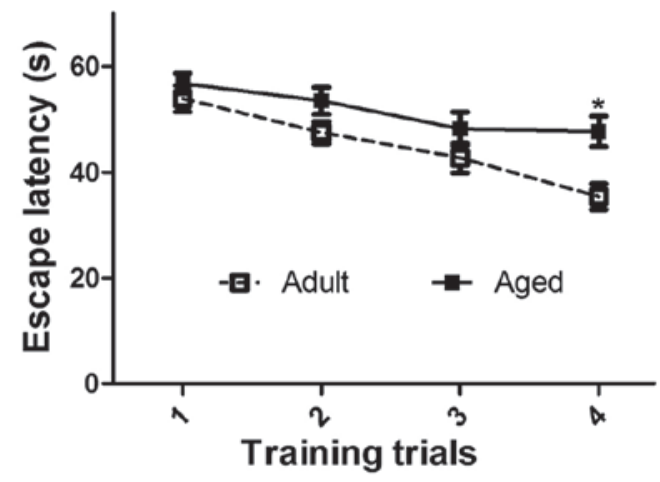

B

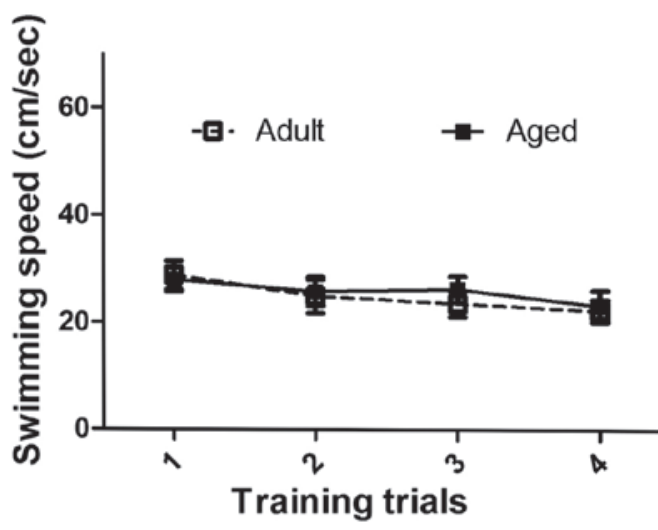

C

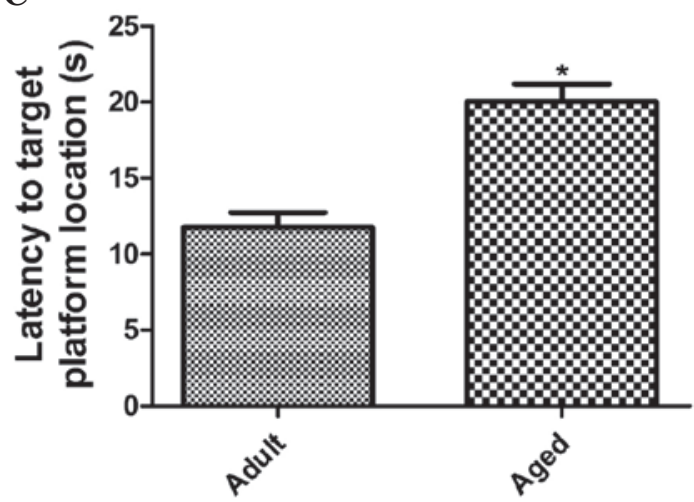

D

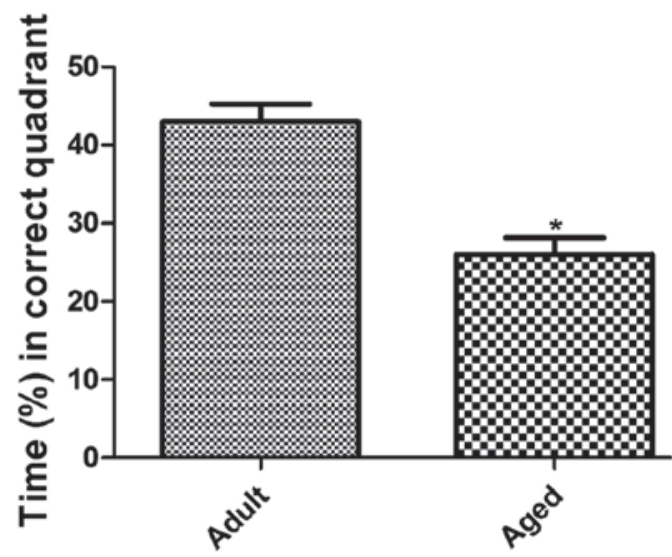

Figure 1. Assessment of spatial memory. (A) Escape latency training trials, (B) average speed $(\mathrm{cm} / \mathrm{sec}),(\mathrm{C})$ escape latency probe trial and (D) time spent in correct quadrant were used to assess young and aged mice in a Morris water maze task. Vales are presented as the mean + standard error of the mean ( $\mathrm{n}=10$ per group). $\mathrm{P}<0.05$, compared with the adult group. 


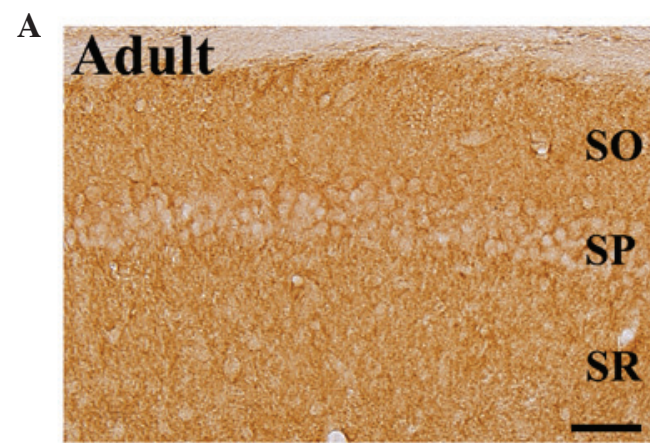

C

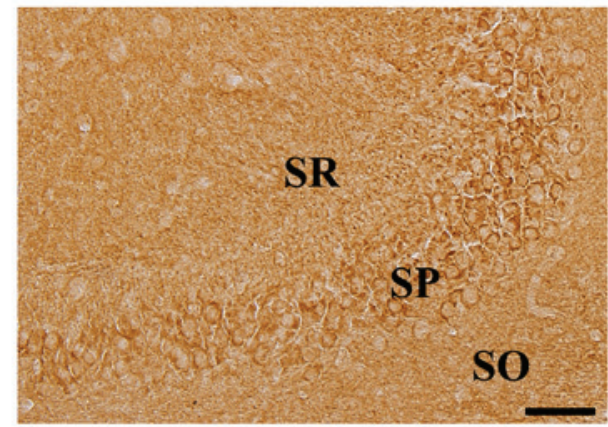

$\mathbf{E}$

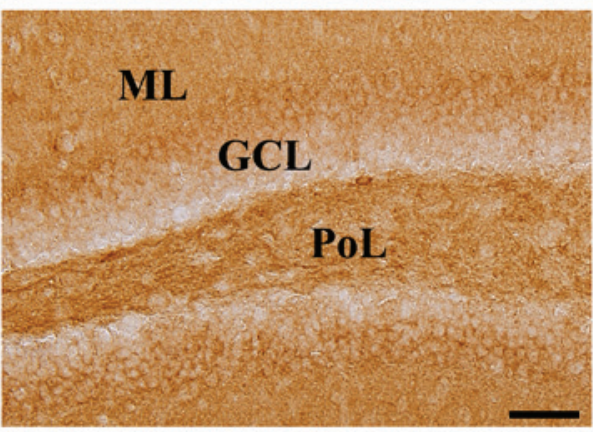

B

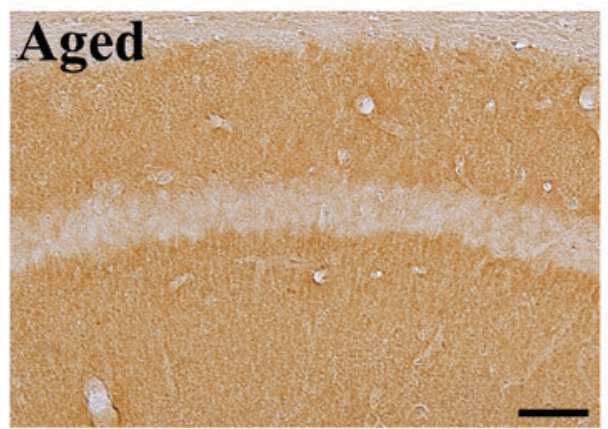

D

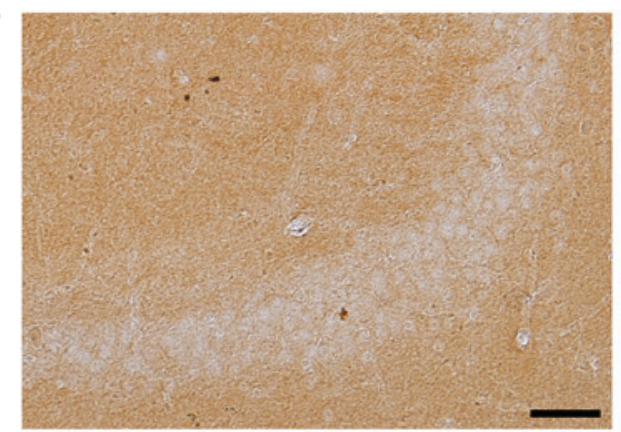

F

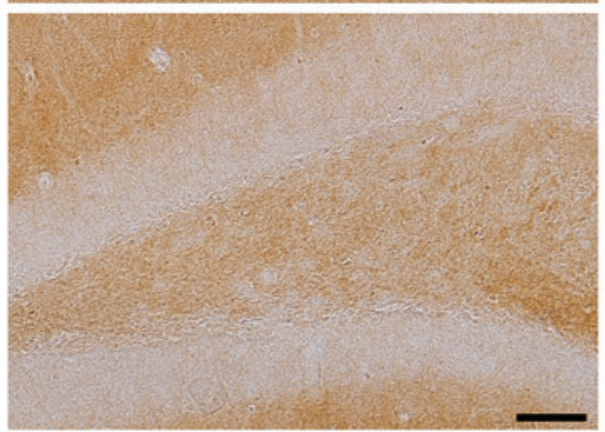

G

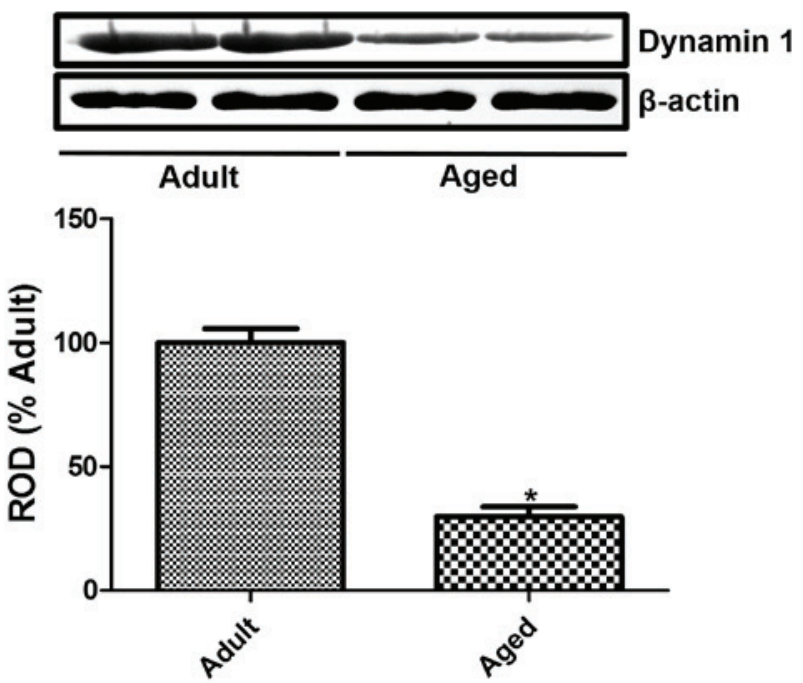

Figure 2. Immunohistochemical assessment of dynamin 1. Immunohistochemistry was used to detect dynamin 1 in the (A) adult and (B) aged hippocampal CA1 region, (C) adult and (D) aged CA3 region, and (E) adult and (F) aged dentate gyrus. In the adult group, dynamin 1 immunoreactivity was found in the SR of the CA1 and CA3 regions, and in the PoL of the dentate gyrus. Dynamin 1 immunoreactivity was also found in the SP of the hippocampal CA1-3 region and GCL of dentate gyrus. In the aged group, dynamin 1 immunoreactivity was detected in these regions at low levels. Scale bar=50 $\mu \mathrm{m}$. (G) Western blot analysis of the protein expression of dynamin 1 in the hippocampi of adult and aged groups. The RODs of the immunoblot bands are shown as percentages ( $\mathrm{n}=6$ per group). Vales are presented as the mean + standard error of the mean. " $\mathrm{P}<0.05$, compared with the adult group. SR, stratum radiatum; SO, stratum oriens; SP, stratum pyramidale; PoL, polymorphic layer; GCL, granule cell layer; ML, molecular layer; ROD relative optical density.

were found between the adult and aged groups in the average swimming speed or the total distance traveled during the probe trial (Fig. 1B).
In the probe trial for the escape latency task, the animals in the aged groups took significantly longer to locate the target platform location, compared with those in the adult group 
$(\mathrm{P}=0.0007$; Fig. 1C). In addition, the aged group spent less time in the correct quadrant, compared with the adult group $(\mathrm{P}=0.0001$; Fig. 1D).

Expression of dynamin 1 in the hippocampus. Changes in the expression of dynamin 1 were examined. In the hippocampal CA1 region of the adult group, the immunoreactivity of dynamin 1 was widely detected in the stratum radiatum and the stratum pyramidale (Fig. 2A). However, in the aged group, immunoreactivity of dynamin 1 was only marginal in the stratum radiatum region of CA1 (Fig. 2B).

In the hippocampal CA3 region of the adult mice, a high level of dynamin 1 immunoreactivity was detected in the pyramidal cell layer. In addition, dynamin 1 was detected in the stratum radiatum (Fig. 2C). However, in the aged group, the immunoreactivity of dynamin 1 was significantly decreased in the pyramidal cell layer and almost absent in the hippocampal CA3 region (Fig. 2D).

In the dentate gyrus of the adult mice, dynamin 1 was found in the outer half of the granule cell layer and the polymorphic layer (Fig. 2E). However, in the aged group, the immunoreactivity of dynamin 1 was significantly decreased in the granule cell layer and the polymorphic layer of the dentate gyrus (Fig. 2F).

The protein levels of dynamin 1 in the aged group were significantly lower, compared with those in the adult group. In the aged group, the protein expression of dynamin 1 was $34.8 \%$ of the expression of dynamin 1 in the adult group (Fig. 2G).

Contextual memory in adult mice following inhibition of dynamin 1. Under basal conditions, the administration of vehicle or dynasore did not lead to any significant differences in freezing between groups. However, following electric and auditory shock, freezing was observed in the vehicle-treated group. In the dynasore-treated group, the level of freezing was significantly decreased, compared with that in the vehicle-treated group (Fig. 3).

\section{Discussion}

There is increasing evidence suggesting that several presynaptic proteins are involved in altering synaptic activity in patients with Alzheimer's disease and in animal models of Alzheimer's disease $(21,25,26)$. In addition, synaptic proteins are essential for the regulation of memory. In the present study, a significant reduction in the spatial memory abilities of the aged group were observed, compared with the adult group, on assessment using the MWM task. The present study then investigated the correlation between the memory impairment observed in the aged group and the expression of dynamin 1. These results suggested that, compared with the adult group, the aged mice used in the present study showed a decline in hippocampal-dependent memory formation. Dynamin 1 is a major dynamin isoform found in neurons (5) and is detected at high levels in presynaptic terminals. In the present study, age-related changes in the expression of dynamin 1 in the hippocampus were observed. The immunoreactivity and protein levels of dynamin 1 were significantly decreased in the hippocampi of the aged group, compared with the levels in the adult group. A reduction in dynamin 1 impairs the axonal trafficking of vesicles through interactions with other endocytotic

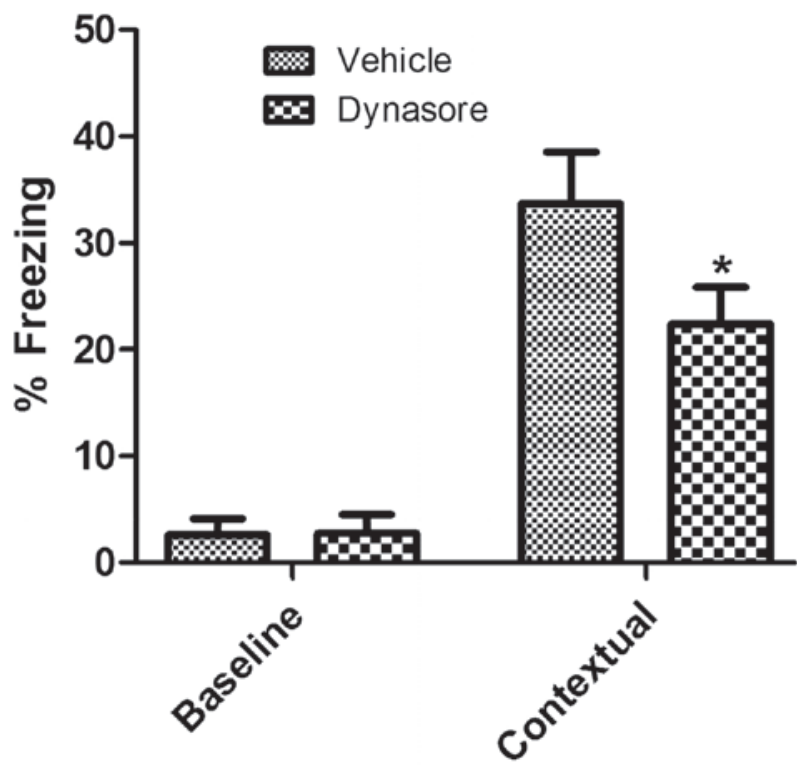

Figure 3. Freezing percentages of vehicle- and dynasore-treated mice in the contextual (electric shock with auditory tone) memory assessment. Vales are presented as the mean + standard error of the mean $\left(n=7\right.$ per group) ${ }^{*} \mathrm{P}<0.05$, compared with the vehicle-treated group.

accessory proteins present in hippocampal neurons $(17,27,28)$. It has also been reported that dynamin 1-depleted neurons accumulate synaptic vesicles at the plasma membrane and decreases the readily releasable pool of synaptic vesicles (29).

However, there have been contradictory reports regarding the changes in the expression levels of dynamin 1 in the brain and its association with age or Alzheimer's disease. A previous study found that the expression level of dynamin 1 was significantly increased overall in the brains of aged (80-week-old) C57BL/6 mice, compared to that in the brains of young (6-week-old) mice (13). However, in the olfactory bulb, the protein expression of dynamin 1 was found to be significantly decreased in the olfactory bulbs of aged (80-week-old) mice, compared with young (6-week-old) mice (12). In a mouse model of Alzheimer's disease, the protein levels of dynamin 1 have been reported to be increased in the brains of $\operatorname{Tg} 2576$ mice with plaque deposition (15) and $\mathrm{APP}_{\mathrm{E} 693 \Delta}$-transgenic mice in the hippocampus (18) based on a proteomic approach. However, these changes to the levels of dynamin 1 in the whole brain or hippocampus were not confirmed by immunohistochemistry or western blot analysis, respectively. Other studies have shown a significant decrease in the mRNA and protein levels of dynamin 1 in the frontal cortex of patients with Alzheimer's disease (21). In addition, the presence of ameyloid $\beta$ induces a significant decrease in the expression of dynamin 1 through the calpain-mediated cleavage of dynamin 1 (16), which is induced by a sustained calcium influx mediated by $N$-methyl-D-aspartate receptors in hippocampal neurons (17). The increase or decrease of dynamin 1 may be associated with the severity of aging or Alzheimer's disease, or the brain regions used for analysis. However, dynamin 1 is likely to be involved in hippocampal-dependent memory formation. In the present study, the involvement of dynamin 1 was demonstrated by directly infusing dynasore, an inhibitor of dynamin 1 , into the hippocampus. This infusion reduced the ability of the mice to perform on hippocampal-dependent memory tasks, 
including the fear-conditioning task. However, no impairment is observed on hippocampal-independent tasks, including cued conditioning (11). The present study also confirmed the effects of dynamin 1 on hippocampal functions using dynasore. The administration of dynasore significantly decreased the contextual memory by electric and auditory shock, compared with that in the vehicle-treated group. This result suggested that dynamin 1 is one of the key factors affecting hippocampal-dependent function.

In conclusion, the immunoreactivity and protein levels of dynamin 1 were found to be significantly reduced in the hippocampus of aged animals, compared with adult mice, and this reduction may be associated with the reduction in hippocampal-dependent memory.

\section{Acknowledgements}

This study was supported by the Priority Research Centers Program through the National Research Foundation of Korea funded by the Ministry of Education, Science and Technology (grant no. NRF-2009-0094071) and the Research Institute for Veterinary Science, Seoul National University (Seoul, Korea).

\section{References}

1. Rosenzweig ES and Barnes CA: Impact of aging on hippocampal function: Plasticity, network dynamics, and cognition. Prog Neurobiol 69: 143-179, 2003.

2. Himeda T, Mizuno K, Kato H and Araki T: Effects of age on immunohistochemical changes in the mouse hippocampus. Mech Ageing Dev 126: 673-677, 2005.

3. Di Stefano G, Casoli T, Fattoretti P, Balietti M, Grossi Y, Giorgetti $\mathrm{B}$ and Bertoni-Freddari C: Level and distribution of microtubule-associated protein-2 (MAP2) as an index of dendritic structural dynamics. Rejuvenation Res 9: 94-98, 2006.

4. Filipek A, Schneider G, Mietelska A, Figiel I and Niewiadomska G: Age-dependent changes in neuronal distribution of CacyBP/SIP: Comparison to tubulin and the tau protein. J Neural Transm (Vienna) 115: 1257-1264, 2008.

5. Ferguson SM, Brasnjo G, Hayashi M, Wölfel M, Collesi C, Giovedi S, Raimondi A, Gong LW, Ariel P, Paradise S, et al: A selective activity-dependent requirement for dynamin 1 in synaptic vesicle endocytosis. Science 316: 570-574, 2007.

6. Fjell AM, McEvoy L, Holland D, Dale AM and Walhovd KB; Alzheimer's Disease Neuroimaging Initiative: What is normal in normal aging? Effects of aging, amyloid and Alzheimer's disease on the cerebral cortex and the hippocampus. Prog Neurobiol 117: 20-40, 2014.

7. Daulatzai MA: Early stages of pathogenesis in memory impairment during normal senescence and Alzheimer's disease. J Alzheimers Dis 20: 355-367, 2010.

8. Watanabe T, Iwasaki K, Takasaki K, Yamagata N, Fujino M, Nogami A, Ii M, Katsurabayashi S, Mishima K and Fujiwara M: Dynamin 1 depletion and memory deficits in rats treated with Abeta and cerebral ischemia. J Neurosci Res 88: 1908-1917, 2010.

9. Sontag JM, Fykse EM, Ushkaryov Y, Liu JP, Robinson PJ and Südhof TC: Differential expression and regulation of multiple dynamins. J Biol Chem 269: 4547-4554, 1994.

10. Clark SG, Shurland DL, Meyerowitz EM, Bargmann CI and van der Bliek AM: A dynamin GTPase mutation causes a rapid and reversible temperature-inducible locomotion defect in C.elegans. Proc Natl Acad Sci USA 94: 10438-10443, 1997.
11. Fà M, Staniszewski A, Saeed F, Francis YI and Arancio O: Dynamin 1 is required for memory formation. PLoS One 9: e91954, 2014.

12. Poon HF, Vaishnav RA, Butterfield DA, Getchell ML and Getchell TV: Proteomic identification of differentially expressed proteins in the aging murine olfactory system and transcriptional analysis of the associated genes. J Neurochem 94: 380-392, 2005.

13. Poon HF, Vaishnav RA, Getchell TV, Getchell ML and Butterfield DA: Quantitative proteomics analysis of differential protein expression and oxidative modification of specific proteins in the brains of old mice. Neurobiol Aging 27: 1010-1019, 2006.

14. Lee $\mathrm{CH}$ and Won $\mathrm{MH}$ : Increased dynamin-1 and -2 protein expression in the aged gerbil hippocampus. Cell Mol Neurobiol 34: 791-796, 2014.

15. Shin SJ, Lee SE, Boo JH, Kim M, Yoon YD, Kim SI and Mook-Jung I: Profiling proteins related to amyloid deposited brain of Tg2576 mice. Proteomics 4: 3359-3368, 2004.

16. Kelly BL, Vassar R and Ferreira A: Beta-Amyloid-induced dynamin 1 depletion in hippocampal neurons. A potential mechanism for early cognitive decline in Alzheimer disease. J Biol Chem 280: 31746-31753, 2005.

17. Kelly BL and Ferreira A: beta-Amyloid-induced dynamin 1 degradation is mediated by $\mathrm{N}$-methyl-D-aspartate receptors in hippocampal neurons. J Biol Chem 281: 28079-28089, 2006.

18. Takano M, Yamashita T, Nagano K, Otani M, Maekura K, Kamada H, Tsunoda S, Tsutsumi Y, Tomiyama T, Mori H, et al: Proteomic analysis of the hippocampus in Alzheimer's disease model mice by using two-dimensional fluorescence difference in gel electrophoresis. Neurosci Lett 534: 85-89, 2013.

19. Hwang YY and Li MD: Proteins differentially expressed in response to nicotine in five rat brain regions: Identification using a 2-DE/MS-based proteomics approach. Proteomics 6: 3138-3153, 2006

20. Xu Q and Li MD: Nicotine modulates expression of dynamin 1 in rat brain and SH-SY5Y cells. Neurosci Lett 489: 168-171, 2011.

21. Yao PJ,Zhu M, Pyun EI, Brooks AI, Therianos S, Meyers VE and Coleman PD: Defects in expression of genes related to synaptic vesicle trafficking in frontal cortex of Alzheimer's disease. Neurobiol Dis 12: 97-109, 2003.

22. Fox JG, Barthold SW, Davisson MT, Newcomer CE, Quimby FW and Smith AL (eds): The Mouse in Biomedical Research: Normative Biology, Husbandry and Models (American College of Laboratory Animal Medicine). Vol 3, 2nd edition. Elsevier, Burlington, 2007.

23. Yoo DY, Kim W, Lee CH, Shin BN, Nam SM, Choi JH, Won MH, Yoon YS and Hwang IK: Melatonin improves D-galactose-induced aging effects on behavior, neurogenesis, and lipid peroxidation in the mouse dentate gyrus via increasing pCREB expression. J Pineal Res 52: 21-28, 2012.

24. Franklin KBJ and Paxinos G (eds): The Mouse Brain in Stereotaxic Coordinates. 4th edition. Academic Press, San Diego, 1997.

25. Leal SL and Yassa MA: Perturbations of neural circuitry in aging, mild cognitive impairment, and Alzheimer's disease. Ageing Res Rev 12: 823-831, 2013.

26. Lithfous S, Dufour A and Després O: Spatial navigation in normal aging and the prodromal stage of Alzheimer's disease: Insights from imaging and behavioral studies. Ageing Res Rev 12: 201-213, 2013.

27. Kitzmueller E, Krapfenbauer K, Hoeger H, Weitzdoerfer R, Lubec $\mathrm{G}$ and Lubec B: Life-long effects of perinatal asphyxia on stress-induced proteins and dynamin 1 in rat brain. Neurochem Res 29: 1767-1777, 2004.

28. Jiang S, Avraham HK, Kim TA, Rogers RA and Avraham S: Receptor-type PTP-NP inhibition of Dynamin-1 GTPase activity is associated with neuronal depolarization. Cell Signal 18: 1439-1446, 2006.

29. Ferguson SM and De Camilli P: Dynamin, a membrane-remodelling GTPase. Nat Rev Mol Cell Biol 13: 75-88, 2012. 